\title{
Metabolic changes in type 2 diabetes are reflected in peripheral blood cells, revealing aberrant cytotoxicity, a viral signature, and hypoxia inducible factor activity
}

Tineke C. T. M. van der Pouw Kraan ${ }^{1 *}$, Weena J. Chen², Mathijs C. M. Bunck², Daniel H. van Raalte², Nynke J. van der Zijl², Renate E. van Genugten², Liselotte van Bloemendaal ${ }^{2}$, Josefien M. Baggen ${ }^{1}$, Erik H. Serné2, Michaela Diamant ${ }^{2 \wedge}$ and Anton J. G. Horrevoets ${ }^{1}$

\begin{abstract}
Background: Metabolic syndrome (MetS) is characterized by central obesity, insulin resistance, dysglycemia, and a pro-atherogenic plasma lipid profile. MetS creates a high risk for development of type 2 diabetes (T2DM) and cardiovascular disease (CVD), presumably by altering inflammatory responses. Presently, it is unknown how the chronic metabolic disturbances in acute hyperglycemia, MetS and T2DM affect the immune activity of peripheral blood cells.

Methods: We performed genome-wide expression analysis of peripheral blood cells obtained from patients with T2DM $(n=6)$ and age-, sex-, BMI- and blood pressure-matched obese individuals with MetS $(n=4)$ and lean healthy normoglycemic controls $(n=3)$, both under fasting conditions and after controlled induction of acute hyperglycemia during a 70 min hyperglycemic clamp. Differential gene expression during fasting conditions was confirmed by real-time $P C R$, for which we included additional age-, sex-, BMI-, and blood pressure-matched obese individuals with $(n=4)$ or without $(n=4)$ MetS.

Results: Pathway and Gene ontology analysis applied to baseline expression profiles of peripheral blood cells from MetS and T2DM patients revealed metabolic changes, highly similar to a reoviral infection gene signature in T2DM patients. Transcription factor binding site analysis indicated that increased HIF-1a activity, a transcription factor induced by either hypoxia or oxidative stress, is responsible for this aberrant metabolic profile in peripheral blood cells from T2DM patients. Acute hyperglycemia in healthy controls resulted in reduced expression of cytotoxicity-related genes, representing NK- and CD8 ${ }^{+}$cells. In obese controls, MetS and especially T2DM patients, baseline expression of genes involved in cytotoxicity was already low, compared to healthy controls and did not further decrease upon acute hyperglycemia.

Conclusions: The reduced activity of cytotoxic genes in T2DM is explained by chronic hyperglycemia, but its acute effects are restricted to healthy controls. Genome expression of circulating leukocytes from T2DM patients differs from MetS individuals by a specific reovirus signature. Our data thus suggest a role for suppressed anti-viral capacity in the etiology of diabetes.
\end{abstract}

\footnotetext{
* Correspondence: t.vanderpouwkraan@vumc.nl

Deceased

'Department of Molecular Cell Biology \& Immunology, VU University Medical

Center, Amsterdam, The Netherlands

Full list of author information is available at the end of the article
} 


\section{Background}

The incidence of metabolic syndrome (MetS) and type 2 diabetes (T2DM) with its associated mortality and morbidity is rapidly increasing in the western world, leading to an extensive medical and societal burden. MetS is defined by a complex set of clinical parameters, which all constitute risk factors for the development of T2DM. These risk factors include central obesity, dyslipidemia (raised triglycerides and lowered high-density lipoprotein cholesterol), high blood pressure, and elevated fasting plasma glucose levels [1].

High blood pressure, hyperglycemia and dislypidemia are held responsible for the increased risk for cardiovascular disease in MetS and T2DM patients, including microvascular complications (including retinopathy, nephropathy and neuropathy) and atherosclerosis at the macrovascular level [1-4]. Both high fasting glucose levels and impaired glucose tolerance are associated with increased cardiovascular events [5], while impaired glucose tolerance predicts cardiovascular death [6]. Intensive glucose control, however, only modestly reduces cardiovascular events $[3,6]$, indicating a more systemic dysregulation in these patients.

T2DM may develop after a stage of insulin resistance in subjects with MetS. However, only approximately one-third of obese, insulin-resistant individuals develop T2DM because of an inability of beta cells to produce sufficient amounts of insulin [7]. Systemic and local activation of the immune system accompanies obesity, and contributes to the development of insulin resistance, T2DM and cardiovascular disease [8,9]. It is not entirely understood which mechanisms trigger the onset of T2DM in subjects at risk, but inflammation is a critical candidate. Pancreatic inflammation in T2DM has been shown by increased local infiltration of macrophages in the beta cell areas $[10,11]$. In animal models for type 2 diabetes, characterization of the increased infiltrating islet-associated macrophages indicated a proinflammatory M1 phenotype, with production of IL-1 $\beta$ and TNF $\alpha$ [12]. Adipose tissue may become a source of inflammation as well, as adipocyte hypertrophy is associated with increased macrophage accumulation, which produce proinflammatory mediators such as TNF $\alpha$ and IL-6, in obese individuals [8]. Trials aimed at inhibition of the immune system by blockade of IL- $1 \alpha$ and $-\beta$ signaling (anakinra) and inhibition of NFKB have shown to reduce HbA1c levels suggesting an effect on beta cell function in patients with T2DM $[7,12]$. In animal models, the IL-1 receptor antagonist reduced the numbers of macrophages in islet areas and improved insulin sensitivity and beta cell function [12]. Infiltrating circulating immune cells are thus important in the development of islet dysfunction, in inflammatory adipose tissue, and in the development of atherosclerotic plaques leading to macrovascular disease. The consequence of acute hyperglycemia on circulating immune cells is largely unknown, but a proinflammatory role for hyperglycemia has been observed, because an oral glucose tolerance test increases transcript levels for ICAM-1, TNF $\alpha$, and IL-6 in peripheral white blood cells from MetS subjects, but not from healthy controls without MetS [13].

Thus blocking inflammation improves glucose tolerance in T2DM patients, but whether in vivo hyperglycemia is able to initiate the activation of the immune system, without the influence of obesity, dyslipidemia, and high blood pressure, is not known. Along this line, it is thus also unknown whether the immune response to acute hyperglycemia is different between healthy subjects and MetS subject and T2DM patients.

Therefore we performed genome-wide expression profiling to achieve an unbiased analysis of the effect of hyperglycemia and T2DM on circulating immune cells. Peripheral blood cells express a large proportion (approximately $80 \%$ ) of the genes encoded in the human genome [14]. In addition, the changes in the expression levels of individual genes reflects changes in the (micro)environment of peripheral blood cells and may also reflect organ-specific changes to the same milieu [14], thus serving as a diagnostic tool for a diseased state. Previous studies using peripheral blood profiling revealed that in T2DM patients the mitochondrial oxidative phosphorylation pathway was affected compared to younger lean controls [15]. This finding is remarkable as a reduced expression of oxidative phosphorylation genes was previously established in muscle tissue from T2DM patients [16]. The immune system is affected by metabolic changes in various organs, and vice versa, the immune system influences metabolic parameters such as insulin resistance. Because of this cross-talk the immune system plays a central role in metabolic changes. To be able to obtain a global and unbiased overview of the changes in the immune system, in response to hyperglycemia and T2DM, we studied the alterations in gene expression in whole blood in T2DM patients in comparison with age-, sex- blood pressure- and BMI- matched MetS subjects and lean controls during fasting conditions and after a well-controlled hyperglycemic clamp. We reasoned that this approach may lead to an improved understanding of the underlying pathology of T2DM and may give leads for medical interventions. The comparison of our data with expression data sets from other studies under various experimental conditions, using pathway analysis, allowed us to identify novel pathological pathways.

\section{Methods}

\section{Patients and controls}

Individuals with MetS and patients with T2DM were recruited by advertisements in local newspapers and studied at the Clinical Research Unit of the Diabetes Center, Department of Internal Medicine at the VU 
University Medical Center (VUMC). MetS was defined according to the criteria of the International Diabetes Federation (IDF) [17]. In short, subjects were eligible when they had a waist of $\geq 94 \mathrm{~cm}$ or more and additionally, two or more of the following criteria: fasting triglycerides $\geq 1.7 \mathrm{mmol} / \mathrm{L}$, HDL cholesterol $<1.03 \mathrm{mmol} / \mathrm{L}$, blood pressure $>130 / 85 \mathrm{mmHg}$ (average of three measurements) or treatment of previously diagnosed hypertension; fasting plasma glucose level (FPG) $\geq 5.6$ and $<7.1 \mathrm{mmol} / \mathrm{L}$.

The response to acute elevations of blood glucose levels in T2DM $(n=6)$, MetS $(n=4)$ and controls $(n=3)$ was measured during the hyperglycemic portion of a combined euglycemic-hyperinsulinemic and hyperglycemicarginine clamp, as described earlier [18]. In short, following the $2 \mathrm{~h}$ euglycemic hyperinsulinemic part of the combined clamp (glucose $5 \mathrm{mmol} / \mathrm{L}$, insulin $600 \mathrm{pmol} / \mathrm{L}$ ), a $1 \mathrm{~h}$ rest period was included to clear the exogenously administered insulin. Thereafter, a hyperglycemic clamp was started, keeping blood glucose at $15 \mathrm{mmol} / \mathrm{L}$ for MetS and T2DM and at $10 \mathrm{mmol} / \mathrm{L}$ in controls. Blood samples were taken at fasting conditions, i.e. $5 \mathrm{~min}$ before the initiation of the clamp and at $70 \mathrm{~min}$ after the start of the glucose clamp in patients and controls. All T2DM patients were on metformin monotherapy. Research involving human subjects (including human material or human data) has been performed with the approval of our local Medical Ethical Committee (in Dutch: Medisch Ethische Toetsingscommissie or METc, of the VU Medical Center (VUmc)). The research carried out on humans is in compliance with the Helsinki Declaration. Written informed consent was obtained from each participant.

\section{Gene expression profiling}

Blood was withdrawn in PAXgene tubes (PreAnalytix, $\mathrm{GmbH}$, Germany) at baseline, i.e. $5 \mathrm{~min}$ before the glucose clamp test, and $70 \mathrm{~min}$ after the hyperglycemic clamp of $10 \mathrm{~mm} / \mathrm{L} 1$ for controls or $15 \mathrm{~mm} / \mathrm{L}$ for T2DM patients and individuals with MetS .

Total RNA was isolated from peripheral blood using the PAXgene RNA isolation kit according to the manufacturers' instructions including a DNAse (Qiagen, Venlo, The Netherlands) step to remove genomic DNA. RNA samples were further processed by ServiceXS (Leiden, The Netherlands). Amplification was performed using the Ambion ${ }^{\circ}$ Illumina TotalPrep RNA Amplification Kit (Ambion, \# IL1791), resulting in biotinylated, amplified cRNA. Labelled RNA samples were hybridized to Sentrix Human HT12v3 Expression bead chip arrays (Illumina, San Diego, CA). Signal was developed with streptavidin$\mathrm{Cy} 3$ and the BeadChip was scanned with the Illumina BeadArray Reader, which is a two-channel, $0.8 \mu \mathrm{m}$ resolution confocal laser scanner, followed by feature extraction. Bead summary intensities were log2-transformed and normalized using quantile normalization [19].

\section{Statistical and biological pathway analysis}

We used Significance Analysis of Microarrays (SAM) [20] for the identification of over- or under-expressed genes after the glucose clamp, applying a two-class paired comparison between samples before and after the clamps. For identification of differences between study groups, we performed a two-class unpaired comparison between MetS - and T2DM individuals. Genes with a false discovery rate $(\mathrm{FDR})<5 \%$ were considered significantly different. Hierarchical clustering [21] of samples was used to visualize the correlation of co-expressed genes in Treeview. For this purpose the genes were expressed relative to the median expression level in all samples (median centered data). For an interpretation of the biological processes that are represented by the genes that show a significantly different level of expression after glucose clamp or between patient groups we used Gene Ontology analysis using the PANTHER-v8.1 (Protein ANalysis THrough Evolutionary Relationships) Classification System at [22], a curated database of protein families, trees, subfamilies and functions. PANTHER uses the binomial statistics tool to compare our gene list to a reference list (NCBI: Homo sapiens genes) to determine the statistically significant over-representation of functional groups of genes. Pathway level analysis [23] of gene expression data was performed by gene set enrichment analysis (GSEA). Pathways comprise lists of genes with a connected biological background and can be used from several sources such as Kyoto Encyclopedia of Genes and Genomes (KEGG), Biocarta, and Reactome databases, user-defined pathways and previously published expression data sets as provided by the Broad institute in the Molecular Signatures database, as described in [24]. We made use of a combination of these pathways provided by the Broad Institute (C2v2 curated geneset), with a minimal geneset size of ten genes, using 1,000 gene set permutations to correct for multiple testing. This type of analysis allows the comparison of our own data with experimental expression data generated by others in an unbiased fashion. Transcription factor binding site analysis was performed on the $500 \mathrm{bp}$ upstream regulatory region of the differentially expressed genes between T2DM and MetS. Lists of significantly different expressed genes between clinical samples were analyzed for enriched transcription factor binding sites by whole genome rVISTA software at [25], using the Transfac database of all transcription factor binding sites (TFBS) conserved in the human to mouse whole genome alignment of March 2006.

RNA isolation, CDNA synthesis, quantitative real-time PCR Total RNA was isolated from peripheral blood using the PAXgene RNA isolation kit according to the manufacturers' instructions including a DNAse (Qiagen, Venlo, The Netherlands) step to remove genomic DNA. RNA 
samples were concentrated by SpeedVac for $30 \mathrm{~min}$. RNA purity and concentration was measured using NanoDrop ND-1,000 Spectrophotometer (Thermo Scientific, Breda, The Netherlands). cDNA was synthesized from 500 ng total RNA per sample using RevertAid ${ }^{\mathrm{ma}} \mathrm{H}$ Minus First Strand cDNA Synthesis Kit (Thermo Fisher Scientific, Waltham, MA, USA) according to the manufacturer's recommendations. Quantitative real-time polymerase chain reaction (PCR) was performed in an ABI PRISM 7900HT system (Applied Biosystems, Foster City, CA, USA), using primers designed by Primer Express version 2.0 (Applied Biosystems):

\begin{tabular}{lll}
\hline Gene & Forward primer & Reverse primer \\
ACTB & 5'GGCACCCAGCACAAT & 5'GCCGATCCACACGGA \\
& GAAG 3' & GTACT 3' \\
CLIC3 & 5'TTCTGGAGGAGACG & 5'TCTTGATGAACGCGGA \\
& CTGG 3' & GAAC 3' \\
PRF1 & 5'AACTITGCAGCCCAGA & 5'TGGAAACTGTAGAAGC \\
& AGACC 3' & GGCAC 3' \\
GZMB & 5'TGCGAATCTGACTAC & 5'GCCTCCAGAGTCCCCC \\
& GCCA 3' & TTAA 3' \\
GNLY & 5'GAGAAACTGCCCAGCA & 5'TGTGCTCTTCCACAGG \\
& GATCT 3' & ACAA 3' \\
KIR2DL4 & 5'ATGAACCAAGAGCCT & 5'TCCAACTGTGCGTATGT \\
& GCGG 3' & CACC 3' \\
\hline
\end{tabular}

Briefly, in a $10 \mu \mathrm{l}$ reaction volume, $4 \mu \mathrm{l}$ of diluted cDNA, $5 \mu \mathrm{l}$ SYBR Green PCR Master Mix (Applied Biosystems), and $0.5 \mathrm{uM}$ of each gene-specific primers were mixed. Gene expression levels were calculated using an arbitrary standard curve and normalized to the human housekeeping gene $\beta$-actin. Comparisons were performed using Student's t-test (two-sided). Differences were considered statistically significant if probability values $(\mathrm{P})$ were less than 0.05 . Results are presented as mean \pm standard error of the mean (SEM).

\section{Results}

Gene expression in peripheral blood cells from T2DM patients differs markedly from both MetS individuals and healthy controls

We compared the baseline gene expression levels of peripheral blood cells from six patients with T2DM to four subjects with MetS, who showed no difference in age, sex, BMI, waist circumference and blood pressure (Table 1). As expected, T2DM patients showed higher fasting plasma glucose (FPG), glycated hemoglobin A1C (HbA1c), while the lipid profile also differed, with higher triglyceride - and lower HDL levels in T2DM, compared to MetS. For comparison, we included healthy lean controls with normal fasting glucose levels and lipid profile, albeit of younger age.
Applying statistical analysis of microarray data (SAM) [20], we identified many genes that were expressed at different levels in T2DM patients versus MetS subjects. We identified 591 genes which were expressed at higher levels and 260 genes expressed at lower levels in T2DM, compared to MetS individuals (at a false discovery rate, FDR of $<5 \%$, see Additional files 1 and 2). In Fig. 1 the differential transcript expression levels in circulating blood cells are visualized after hierarchical clustering of the genes. Although the lean controls were not part of this statistical analysis, we visualized their expression levels for the genes that were differentially expressed between T2DM and MetS to mark the strong resemblance of lean controls with the MetS subjects. As expected, an increased expression of proinflammatory marker genes was detected in T2DM patients, compared to MetS. These genes include: S100A12 (or EN-RAGE, extracellular newly identified receptor for advanced glycation end products-binding protein, (2.6 fold increase in T2DM, $\mathrm{FDR}=1.97 \%$ ), CD164 (2.75 fold increase, FDR $<0.1 \%$ ), TLR1 (2.8 fold increase, FDR $<0.1 \%$ ). In addition, T2DM patients expressed higher levels of the regulator of energy balance, leptin ( 1.5 fold increase, FDR $=4.1 \%$ ), and of the anti-oxidant gene catalase (2.0 fold increase, $\mathrm{FDR}=4.1 \%)$.

\section{Pathway and gene set analysis identifies a reovirus signature in T2DM patients}

The Panther classification system was used to determine which biological processes were represented by the differentially expressed genes in the T2DM patients versus MetS individuals by applying the statistical overrepresentation test (Fisher's exact). Both the group of genes that were expressed at higher levels and the panel of genes which were expressed at lower levels were involved in broadly defined metabolic processes (Table 2). These data indicate that a disturbance of systemic metabolism is reflected in gene expression patterns in peripheral blood cells in patients with T2DM. Applying the same analysis in T2DM patients versus controls, we also detected significant metabolic differences, albeit at lower levels of statistical significance, due to the low number of controls.

To obtain more insight into the pathology behind the differences in gene expression, we applied pathway analysis using Gene Set Enrichment Analysis (GSEA, [23]). This analysis allowed us to compare a wide array of published genome expression data sets, defined by experimental conditions or disease states, to our own data (Table 3 and Fig. 2). Strikingly, from over 1,500 pathways (GSEA functional gene set, C2v2) analyzed, the most significant T2DM-associated gene set, comprised genes which were previously identified as being upregulated by reovirus infection [26]. Concordantly, also one of the most 
Table 1 Characteristics of the groups of patients for which genome-wide expression profiling was performed

\begin{tabular}{|c|c|c|c|c|c|c|}
\hline & $\mathrm{T} 2 \mathrm{DM}$ & MetS & Healthy controls & $p$-value & & \\
\hline & $n=6$ & $n=4$ & $n=3$ & T2DM vs C & MetS vs C & MetS vs T2DM \\
\hline Age (years) & 59.2 & 60.9 & 22.7 & $<0.0001$ & 0.001 & 0.76 \\
\hline $\operatorname{Sex}(m / f)$ & $6 / 0$ & $3 / 1$ & $3 / 0$ & 1 & 1 & 0.40 \\
\hline Height (cm) & 172.2 & 174.9 & 187.3 & 0.001 & 0.09 & 0.59 \\
\hline Weight (kg) & 84.2 & 83.4 & 74.2 & 0.14 & 0.36 & 0.91 \\
\hline BMI (kg/m2) & 28.5 & 27.1 & 21.1 & 0.02 & 0.03 & 0.56 \\
\hline Waist (cm) & 102.1 & 97.6 & 79.2 & 0.02 & 0.07 & 0.57 \\
\hline Syst. BP (mm Hg) & 143.5 & 133.7 & 114.7 & 0.02 & 0.06 & 0.32 \\
\hline Diast. BP (mm Hg) & 85.3 & 84.2 & 70 & 0.03 & 0.06 & 0.87 \\
\hline FPG (mmol/l) & 8.4 & 6.7 & 4.6 & 0.0002 & 0.0008 & 0.005 \\
\hline HbA1c (\%) & 6.6 & 5.9 & na & na & na & 0.10 \\
\hline Tot Chol (mmol/l) & 4.8 & 5.2 & 4.4 & 0.51 & 0.24 & 0.48 \\
\hline $\mathrm{HDL}(\mathrm{mmol} / \mathrm{l})$ & 1.1 & 1.7 & 1.6 & 0.006 & 0.52 & 0.002 \\
\hline LDL (mmol/l) & 3 & 3 & 2.4 & 0.34 & 0.25 & 0.97 \\
\hline TG $(m m o l / l)$ & 1.9 & 1 & 0.9 & 0.02 & 0.66 & 0.01 \\
\hline
\end{tabular}

BMl; body mass index, Syst BP; systolic blood pressure, Diast BP; diastolic BP, FPG; fasting plasma glucose, HbA1c; hemoglobin A1c, Tot Chol; Total cholesterol, HDL; high density lipoproteins, LDL; low density lipoproteins, TG; triglycerides, na; not available, $p$-values were calculated by Student's T-test, or Fisher's exact for sex. $p$ values $<0.05$ were considered significant (highlighted in bold)

significant pathways for genes which were expressed at lower levels in T2DM vs MetS patients were genes downregulated by reovirus infection. The reovirus signature was generated in vitro in Human Embryonic Kidney (HEK293) cells. Because of this unexpected finding we searched for other published virus-induced genesets derived from infected circulating blood cells, thus more comparable to our study. We found two more relevant and more physiological data sets, i.e. ex vivo virus infection-induced profiles in PBMC from infected children. One set was derived from children infected with a closely related RNA virus, Rotavirus, another member of the Reoviridae family [27]. Another set was derived from a study in which infection with a more distantly related RNA virus, the Influenza virus was analyzed [28]. In both studies gene expression in PBMC from infected children was compared to PBMC from healthy children. The Rotavirus signature was also significantly associated with T2DM, Rotavirus-induced genes were upregulated in T2DM patients (Fig. 2 and Table 3), while Rotavirus-repressed genes were downregulated in T2DM patients. The signature of the Influenza virus was not associated with T2DM (Influenza-induced genes, $\mathrm{FDR}=0.43$ (or $43 \%$ ), Influenza-repressed genes, $\mathrm{FDR}=0.14$, data not shown). Because type I interferon is typically induced by viral infections we also included an ex vivo type I interferon-induced geneset in PBMC from IFN $\alpha$-treated patients [29]. The type I IFN-induced geneset was also significantly increased in T2DM (Table 3 and Fig. 2). The IFN response in T2DM was also indicated by the significant geneset: GRANDVAUX_IRF3_UP, containing genes up-regulated in Jurkat T cells by expression of a constitutively active form of IRF3, which is normally activated during viral infections and induces type I IFNs [30]. In Fig. 2 the reoviral signatures are represented, showing the enriched genes: 73 reoviral genes were enriched in T2DM; expressed at high levels in T2DM out of the 227 reovirus-induced genes and also 73 reovirus-repressed genes were enriched; expressed at low levels in T2DM out of the 214 reovirus-repressed genes. Similar results are shown for the Rotavirus- and IFNa-induced signatures. Thus, gene expression profiles in peripheral blood cells induced by T2DM show a significant and specific pattern, similar to the modulatory effect of reovirus infection. We included a Venn diagram (Fig. 3), visualizing the overlap of the enriched genes in T2DM patients for the four virus infection-associated genesets. This diagram shows that the genes induced by the three virus types all contain IFN $\alpha$ induced genes, in particular Influenza (11 out of 28 genes), and that 57 genes are uniquely induced by reovirus.

Although the healthy controls were not matched for age and BMI, we did perform pathway analysis and confirmed the previously reported reduced expression of genes representing electron transport chain and oxidative phosphorylation in T2DM compared to significantly younger lean controls (FDR $<0.015$, data not shown) [15], while the reovirus signatures were also highly significantly present when we compared T2DM to young lean controls (data not shown). 


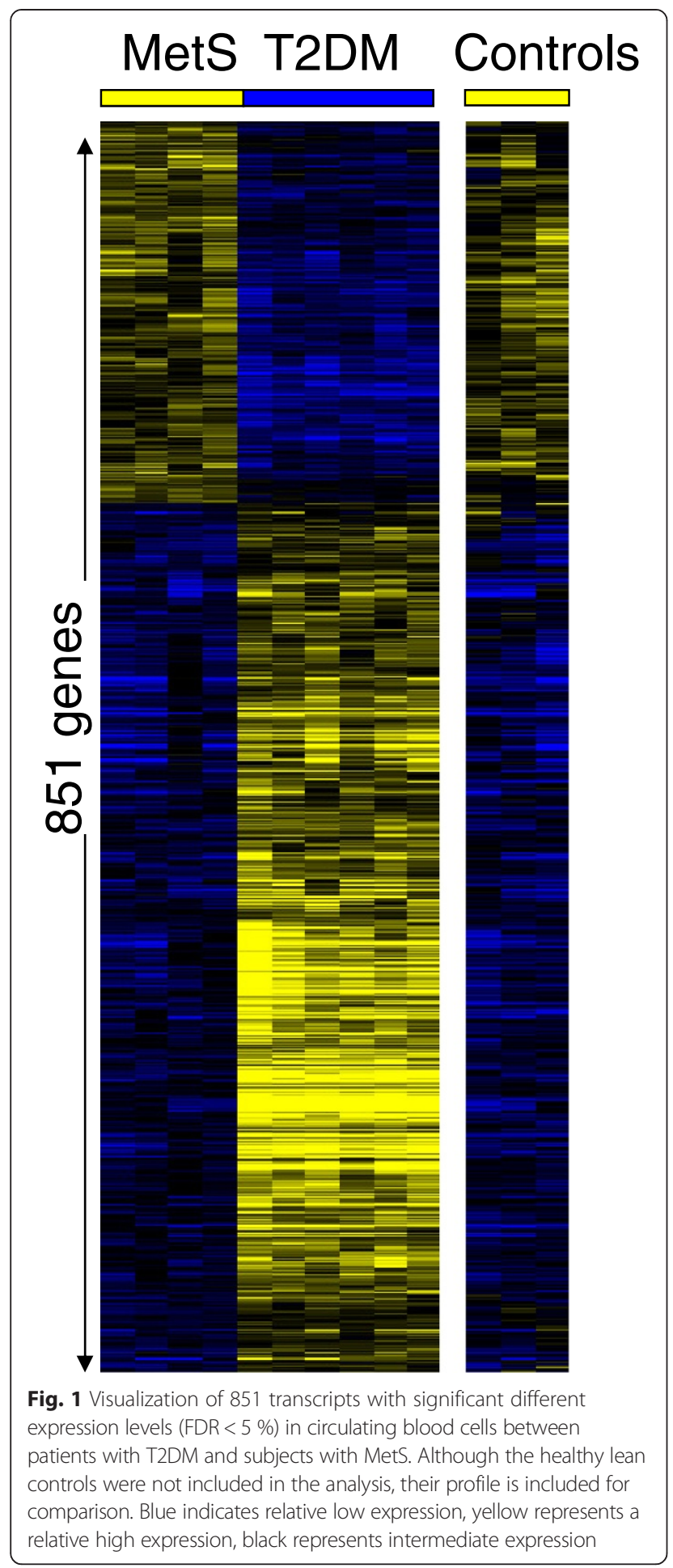

Both T2DM and reoviral infection induce HIF-1 dependent metabolic gene profiles in peripheral blood cells

We next analyzed all genes which were upregulated by reovirus $(n=226)$, as published [26] and for the genes which were both upregulated by reovirus and by T2DM $(n=73)$, as identified by our GSEA analysis for involvement in metabolic processes. The same gene ontology analysis was performed for the genes which were downregulated by reovirus. In all of these analyses, metabolic processes were (among) the most significant processes represented by all gene sets, indicating that reovirus induces similar metabolic changes as the metabolic abnormalities observed in T2DM patients (Table 4). The 57 unique reovirus-induced genes, indicated in Fig. 3, indeed represent the metabolic processes from Table 4; nucleobase, nucleoside, nucleotide and nucleic acid metabolic process, primary metabolic processes, metabolic processes, protein amino acid phosphorylation (all $\mathrm{p}<0.001)$ and monosaccharide metabolic process $(\mathrm{p}=$ $0.004)$.

To identify which factor(s) may have caused the altered gene expression in T2DM patients, we performed a transcription factor binding site analysis (Table 5). The most significant enriched binding site in the upstream regulatory region of genes which were expressed at higher levels in T2DM patients versus MetS was HIF1 $\left(\mathrm{p}=1.25 \times 10^{-12}\right.$, Table 5A). HIF1 comprises the binding site for the heterodimeric protein consisting of HIF-1 $\alpha$ and the constitutively expressed HIF-1 $\beta$ (also termed ARNT) and is a major regulator of metabolic processes as its activity is controlled by either hypoxia or oxidative stress. Interestingly, also ARNT binding sites were significantly overexpressed in this gene set $\left(\mathrm{p}=2.33 \times 10^{-6}\right.$, Table 5A). In a comparison between T2DM patients and lean controls, the significantly higher expressed genes in T2DM also showed enriched binding sites for HIF1 and $\operatorname{ARNT}\left(\mathrm{p}=1 \times 10^{-16}\right.$ and $\mathrm{p}=7.6 \times 10^{-9}$ respectively), for lower expressed genes HIF1 was again also enriched $\left(\mathrm{p}=7.1 \times 10^{-5}\right.$, data not shown). Our data thus indicate that HIF-1 $\alpha$ /ARNT may regulate the expression of the genes involved in metabolic processes as identified from the gene ontology analysis.

\section{Identification of a cytotoxicity profile with a blunted response to in vivo acute hyperglycemia in T2DM blood cells}

To study the impact of acute hyperglycemia on the expression patterns in circulating leukocytes in the respective study groups, we analyzed alterations in gene expression profiles in T2DM patients, individuals with MetS and healthy controls in response to a hyperglycemic clamp (paired analysis, ANOVA). Only a limited number of genes per group changed in expression after exposure to acute elevations of blood glucose, and none of the genes showed altered expression upon hyperglycemia in all three groups (Table 6). The T2DM group hardly responded to the hyperglycemic clamp as only 3 genes were downregulated (TSC22D3, DUSP1, and MCL1). In individuals with MetS, four genes were down-regulated after the 70 min hyperglycemic clamp, including C1orf162, 
Table 2 Gene ontology analysis of genes expressed at higher and lower levels in T2DM vs MetS

\begin{tabular}{|c|c|c|c|}
\hline \multicolumn{4}{|l|}{$\mathrm{GO}$ analysis of genes expressed at higher levels in T2DM vs MetS: } \\
\hline Biological process & $\mathrm{nr}$ in genome & $\mathrm{nr}$ sign genes & $p$-value \\
\hline Metabolic process & 8,127 & 183 & $5.13 \mathrm{E}-04$ \\
\hline Primary metabolic process & 7,813 & 175 & $1.06 \mathrm{E}-03$ \\
\hline Protein transport & 1,542 & 44 & $3.29 \mathrm{E}-03$ \\
\hline Intracellular protein transport & 1,542 & 44 & $3.29 \mathrm{E}-03$ \\
\hline Cell cycle & 1,602 & 45 & $3.94 \mathrm{E}-03$ \\
\hline \multicolumn{4}{|l|}{ GO analysis of genes expressed at lower levels in T2DM vs MetS: } \\
\hline Metabolic process & 8,127 & 113 & $1.15 \mathrm{E}-06$ \\
\hline Primary metabolic process & 7,813 & 109 & 2.04E-06 \\
\hline Translation & 453 & 14 & 1.75E-04 \\
\hline Organelle organization & 295 & 11 & 1.83E-04 \\
\hline Nucleobase, nucleoside, nucleotide and nucleic acid metabolic process & 3,782 & 58 & 2.04E-04 \\
\hline Establishment or maintenance of chromatin architecture & 269 & 10 & $3.68 \mathrm{E}-04$ \\
\hline Protein metabolic process & 3,178 & 49 & $6.75 E-04$ \\
\hline Transcription from RNA polymerase II promoter & 2,214 & 37 & $8.63 \mathrm{E}-04$ \\
\hline RNA metabolic process & 663 & 16 & $9.19 \mathrm{E}-04$ \\
\hline Transcription & 2,224 & 37 & 9.36E-04 \\
\hline Cell cycle & 1,602 & 29 & $1.02 \mathrm{E}-03$ \\
\hline Nuclear mRNA splicing, via spliceosome & 371 & 11 & $1.21 \mathrm{E}-03$ \\
\hline Cellular component organization & 1,255 & 24 & $1.39 \mathrm{E}-03$ \\
\hline mRNA processing & 456 & 12 & $1.98 \mathrm{E}-03$ \\
\hline Hemopoiesis & 183 & 6 & 9.83E-03 \\
\hline
\end{tabular}

Granzym B, FKBP5, and TSC22D3. Two genes were significantly up-regulated by high glucose levels in the MetS group: IL-8 en HIV-1 Tat specific factor one pseudogene (LOC401233). In the control group we identified nine genes which were down-regulated after in vivo exposure to high glucose, while none of the genes showed up-regulation. Remarkably, five out of nine glucose-responsive down-regulated genes in controls have a documented role in immune cell-induced cytoxicity: chloride intracellular channel 3 (CLIC3), killer cell immunoglobulin-like receptor, two domains, long cytoplasmic tail, 4 (KIR2DL4), perforin 1 (PRF1), Granzym B (GZMB) and granulysin (GNLY). These genes are typically expressed in cells with cytotoxic functions, like NK cells [31] and $\mathrm{CD}^{+} \mathrm{T}$ cells [32, 33]. Overall, the limited overlaps in response to high glucose between the three groups places the MetS group as an intermediate between controls and T2DM patients, corresponding with their intermediate clinical parameters (Table 1). Because the cellular composition will affect the gene expression profile, we included cellspecific genesets in the pathway analysis; T cells, CD8 T cells, granulocytes, B cells, and lymphocytes [34], and our own previously published cytotoxic NK cell dataset [35]. Including these genesets in our pathway analysis led to the identification of the cytotoxic cell subset as the most significant geneset with reduced expression in T2DM patients (Fig. 2 and Table 3). In addition, profiles specific for cytotoxic CD8 cells (Table 3) and to a lesser extend B cells (data not shown, FDR $=0.03$ ) were reduced in the T2DM patients compared to MetS.

Thus, the genes which were downregulated by high glucose levels in controls were already expressed at lower levels in T2DM patients, most likely due to chronic high glucose levels. The five cytotoxicity-related genes that were downregulated by hyperglycemia in controls all showed the same expression pattern across the patient groups. We therefore averaged the expression of these five genes in each individual at each time point to visualize the transcript levels (Fig. 4). The average expression at baseline was 2.3 fold lower in T2DM compared to controls $(\mathrm{p}=0.003)$ and MetS subjects showed a 1.5 fold lower expression compared to controls $(\mathrm{p}=0.03)$. To establish whether obesity, without MetS was also affecting the expression levels of these cytotoxic genes, and to confirm the observed baseline differences by an independent technique, we performed baseline gene quantification by real-time PCR in a larger sample set (Table 7). We included four age-, sex-, blood pressure-, and BMI- matched (obese) controls (not fulfilling the 
Table 3 Gene set enrichment analysis

\begin{tabular}{|c|c|c|c|c|}
\hline \multicolumn{5}{|c|}{$\begin{array}{l}\text { A. Significant gene sets expressed at higher levels in } \\
\text { T2DM vs MetS subjects }\end{array}$} \\
\hline Name & Size & NES & NOM $p$-val & FDR q-val \\
\hline DEBIASI_REOVIRUS_HEK293_UP & 227 & -2.08 & 0.000 & 0.024 \\
\hline JIIFNA_INDUCED_PBMC_EX_VIVO & 325 & -2.05 & 0.000 & 0.024 \\
\hline ROTH_HTERT_UP & 14 & -2.03 & 0.000 & 0.020 \\
\hline $\begin{array}{l}\text { FLECHNER_KIDNEY_TRANSPLANT_ } \\
\text { WELL_UP }\end{array}$ & 496 & -1.98 & 0.000 & 0.034 \\
\hline UVB_SCC_UP & 83 & -1.96 & 0.000 & 0.042 \\
\hline $\begin{array}{l}\text { MMS_HUMAN_LYMPH_LOW_ } \\
\text { 4HRS_DN }\end{array}$ & 16 & -1.94 & 0.000 & 0.046 \\
\hline GRANDVAUX_IRF3_UP & 13 & -1.94 & 0.000 & 0.041 \\
\hline CHEN_HOXA5_TARGETS_UP & 195 & -1.92 & 0.000 & 0.045 \\
\hline DORSAM_HOXA9_DN & 30 & -1.92 & 0.000 & 0.042 \\
\hline DORSAM_HOXA9_UP & 32 & -1.89 & 0.002 & 0.062 \\
\hline HDACI_COLON_SUL12HRS_DN & 26 & -1.88 & 0.000 & 0.059 \\
\hline $\begin{array}{l}\text { WANG_ROTAVIRUS_INFECTION_ } \\
\text { PBMC_UP }\end{array}$ & 48 & -1.88 & 0.000 & 0.056 \\
\hline $\begin{array}{l}\text { MMS_MOUSE_LYMPH_HIGH_ } \\
\text { 4HRS_UP }\end{array}$ & 35 & -1.87 & 0.000 & 0.062 \\
\hline TAKEDA_NUP8_HOXA9_3D_DN & 28 & -1.86 & 0.002 & 0.069 \\
\hline ZUCCHI_EPITHELIAL_UP & 42 & -1.84 & 0.000 & 0.082 \\
\hline \multicolumn{5}{|c|}{$\begin{array}{l}\text { B. Significant gene sets expressed at lower levels } \\
\text { in T2DM vs MetS subjects }\end{array}$} \\
\hline Name & Size & NES & NOM p-val & FDR q-val \\
\hline POUWKRAAN_CYTOTOXIC_CELLS & 57 & 2.29 & 0 & 0.000 \\
\hline DEBIASI_REOVIRUS_HEK293_DN & 214 & 2.10 & 0 & 0.003 \\
\hline BASSO_REGULATORY_HUBS & 129 & 2.09 & 0 & 0.002 \\
\hline LIN_WNT_UP & 51 & 2.08 & 0 & 0.002 \\
\hline ROSS_MLL_FUSION & 73 & 2.05 & 0 & 0.002 \\
\hline BRCA1_OVEREXP_DN & 102 & 2.01 & 0 & 0.005 \\
\hline PALMER_CD8_CELLS & 16 & 2.01 & 0 & 0.004 \\
\hline YU_CMYC_DN & 44 & 2.01 & 0 & 0.004 \\
\hline FALT_BCLL_UP & 43 & 2.00 & 0 & 0.004 \\
\hline $\begin{array}{l}\text { WANG_ROTAVIRUS_INFECTION_ } \\
\text { PBMC_DN }\end{array}$ & 133 & 1.97 & 0 & 0.007 \\
\hline FERRANDO_MLL_T_ALL_UP & 86 & 1.97 & 0 & 0.006 \\
\hline DNA_REPLICATION_REACTOME & 44 & 1.88 & 0 & 0.025 \\
\hline ET743_HELA_DN & 17 & 1.87 & 0 & 0.027 \\
\hline NING_COPD_UP & 141 & 1.86 & 0 & 0.030 \\
\hline NAKAJIMA_MCSMBP_MAST & 47 & 1.86 & 0 & 0.029 \\
\hline
\end{tabular}

The top 15 significant pathways are listed, ranked on Normalized Enrichment Score (NES)

MetS criteria), and we included four additional MetS subjects. We quantified the four most significantly downregulated genes after hyperglycemia (selected from Table 6), which all showed a similar expression pattern among the four groups (Fig. 5). We confirmed that expression levels were highest in the lean control group, compared to all other groups ( $\mathrm{p}<0.05$ for CLIC3 and Granzym B) or compared to obese controls and MetS ( $\mathrm{p}<0.05$ for Perforin). Expression levels were again lowest in T2DM, compared to MetS and controls, reaching statistical significance for CLIC3 and Granzyme B $(\mathrm{p}<0.05)$. Obese controls were not significantly different from MetS subjects or T2DM patients, although the sample size was small $(\mathrm{n}=4)$.

Our results indicate that cytotoxic genes are downregulated in peripheral blood cells by high glucose levels, are expressed at lower levels in T2DM patients compared to MetS subjects and lean controls. Furthermore, these genes may also be affected by obesity and age.

\section{Discussion}

Peripheral blood cells in T2DM are chronically exposed to abnormally high levels of glucose, due to the beta cell dysfunction in the presence of insulin resistance.

After imposing acute hyperglycemia in vivo in control individuals by applying a $70 \mathrm{~min}$ hyperglycemic clamp, we observed a markedly reduced expression of cytotoxicity-related genes. In T2DM patients the expression levels of these cytotoxic genes were already low, and were hardly affected by the hyperglycemic clamp. MetS subjects showed an intermediate response. We thus provide evidence that the reduced expression of cytotoxic genes is a direct consequence of high glucose levels. We did not observe a difference in baseline cytotoxic gene expression between age- and BMI-matched obese controls and MetS subjects, indicating that age and obesity may contribute to the low expression of cytotoxicity genes. In mice, cytotoxic gene expression declines with old age which is correlated with a reduced cytolytic capacity of cytotoxic T cells [36]. For humans, it has been reported that the functional capacity of virus-specific cytotoxic $\mathrm{CD}^{+} \mathrm{T}$ cells diminishes after the age of sixty [37]. High glucose levels may therefore accelerate the decline of functional $\mathrm{CD}^{+}$cells in MetS and especially T2DM patients (mean age was 59-60 years). This decline may influence the risk of cardiovascular disease, as experimental injury-induced arterial neointima formation is reduced by the most lytic fraction of $\mathrm{CD}^{+}$cells, due to lysis of vascular smooth muscle cells $[38,39]$, while $\mathrm{CD}^{+}$cells also mediate the athero-protective effect of immunization with an ApoB100 peptide [39].

Our pathway analysis confirmed a low expression of effector cytotoxic cells in T2DM patients compared to MetS subjects, most likely indicating a reduced number of circulating cytotoxic cells, as was observed in azathioprine-treated Crohn's Disease patients [35]. A reduced lytic cell activity, may lead to an increased vulnerability for viral infections and tumor development in the host. $\mathrm{CD}^{+}$cytotoxic $\mathrm{T}$ cells and NK cells are 

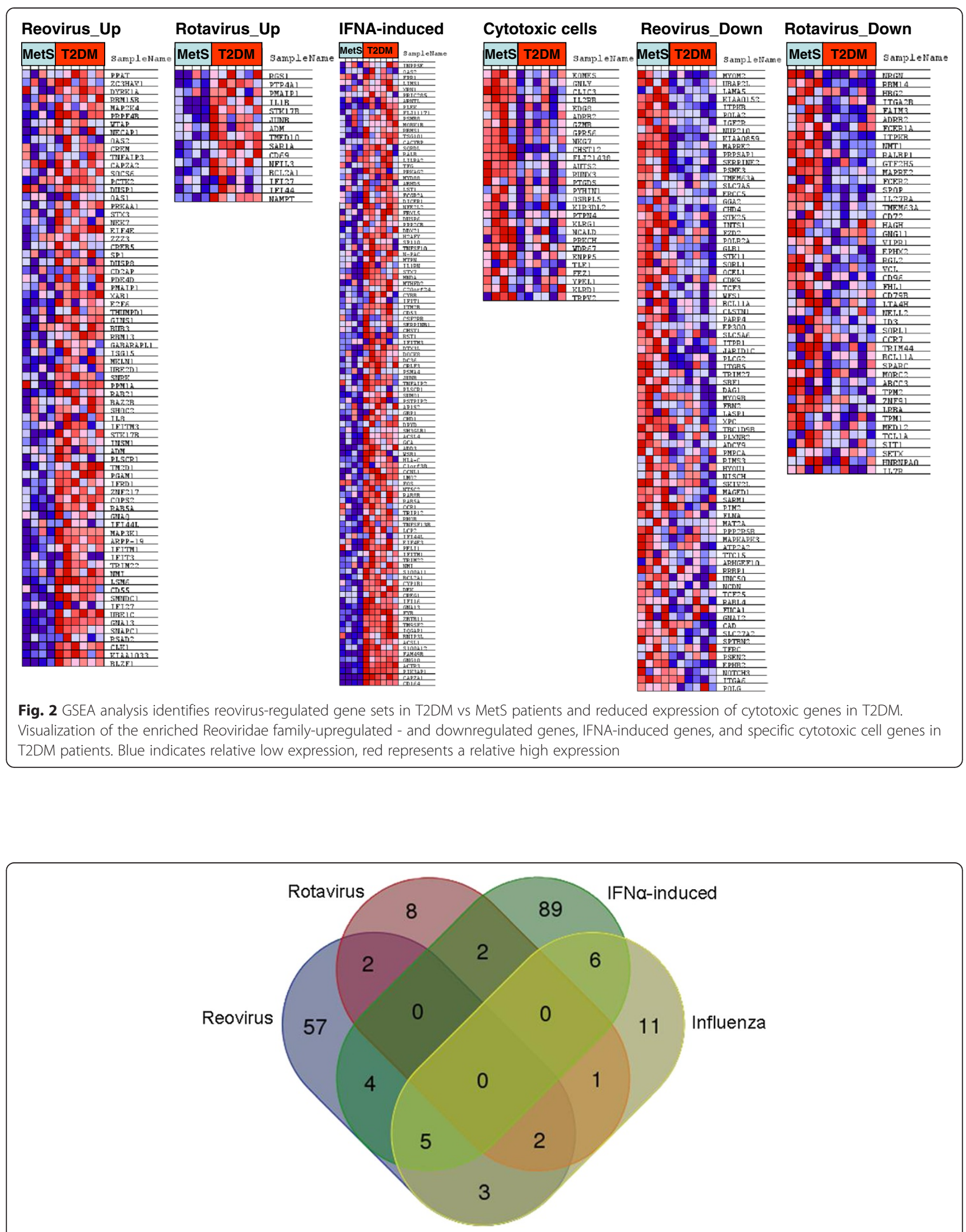

Fig. 3 Venn diagram of enriched genes in T2DM from 4 genesets. Visualization of the overlap of the enriched genes in T2DM patients for the four virus infection-associated genesets 
Table 4 Gene ontology (GO) analysis of genes related to reovirus infection [26]

\begin{tabular}{|c|c|c|c|c|c|}
\hline \multicolumn{2}{|l|}{ GO analysis of genes expressed at higher levels in reovirus-infected cells: } & \multicolumn{2}{|l|}{ Upreg. in RI } & \multicolumn{2}{|c|}{ Upreg in $\mathrm{Rl}$, and T2DM } \\
\hline Biological Process & $\mathrm{nr}$ in genome & $\mathrm{nr}$ sign genes & $p$-value & $\mathrm{nr}$ sign genes & $p$-value \\
\hline nucleobase, nucleoside, nucleotide and nucleic acid metabolic process & 3782 & 75 & 7.78E-09 & 22 & $5.74 \mathrm{E}-03$ \\
\hline primary metabolic process & 7813 & 120 & $9.01 \mathrm{E}-08$ & 40 & 7.65E-04 \\
\hline metabolic process & 8127 & 120 & $1.03 \mathrm{E}-06$ & 40 & 1.87E-03 \\
\hline response to interferon-gamma & 113 & 9 & $3.90 \mathrm{E}-06$ & 5 & 4.46E-05 \\
\hline intracellular signaling cascade & 1492 & 34 & $1.68 \mathrm{E}-05$ & 11 & 1.16E-02 \\
\hline monosaccharide metabolic process & 202 & 10 & $6.56 \mathrm{E}-05$ & 6 & $6.80 \mathrm{E}-05$ \\
\hline protein amino acid phosphorylation & 654 & 19 & 7.17E-05 & 12 & $1.97 \mathrm{E}-06$ \\
\hline response to stress & 496 & 16 & 8.33E-05 & 6 & $6.86 \mathrm{E}-03$ \\
\hline MAPKKK cascade & 454 & 15 & 1.07E-04 & 5 & 1.93E-02 \\
\hline cell cycle & 1602 & 31 & $7.28 \mathrm{E}-04$ & 9 & 9.23E-02 \\
\hline protein modification process & 1330 & 23 & $1.32 \mathrm{E}-02$ & 13 & 4.87E-04 \\
\hline \multicolumn{2}{|l|}{ GO analysis of genes expressed at lower levels in reovirus-infected cells: } & \multicolumn{2}{|l|}{ Downreg. in $\mathrm{Rl}$} & \multicolumn{2}{|c|}{ Downreg in $\mathrm{Rl}$, and T2DM } \\
\hline Biological Process & $\mathrm{nr}$ in genome & $\mathrm{nr}$ sign genes & $p$-value & $\mathrm{nr}$ sign genes & $p$-value \\
\hline primary metabolic process & 7813 & 110 & 3.70E-06 & 41 & $2.28 \mathrm{E}-03$ \\
\hline metabolic process & 8127 & 113 & 4.35E-06 & 41 & 5.27E-03 \\
\hline cell adhesion & 1301 & 29 & 4.56E-05 & 11 & 7.40E-03 \\
\hline protein modification process & 1330 & 29 & $6.72 \mathrm{E}-05$ & 11 & 8.66E-03 \\
\hline protein amino acid phosphorylation & 654 & 18 & 1.17E-04 & 7 & 9.91E-03 \\
\hline
\end{tabular}

GO analysis was performed on genes which were expressed at higher or lower levels after reovirus infection (RI), and of reovirus-regulated genes that were either up- or down regulated in T2DM vs MetS individuals, identified by gene set enrichment analysis. $P$-values $<10 \mathrm{E}-4$ are included if reached for one of the analyses

required for anti-viral and anti-tumor responses through their lytic activity (mediated by granzymes, granulysin and perforin) and non-lytic mechanisms through release of anti-viral cytokines [40, 41]. Thus a low activity of cytotoxic cells, indicated by the reduced expression of these genes in T2DM patients may cause an impaired response to cancer and viral infections. The incidence of cancer is indeed higher in subjects with MetS and T2DM [42]. For hepatocellular carcinoma in chronic hepatitis $\mathrm{C}$ patients the increased incidence in T2DM patients is also related to high concentrations of glycosylated hemoglobin (HbA1c), corresponding with our finding that hyperglycemia reduces cytotoxic genes. Active viral infections may also be more common in diabetes, suggested by the increased incidence of cytomegalovirus in atherosclerotic lesions in arteries from patients with T2DM [43], a virus which usually reactivates in immunocompromised hosts. The detrimental effect of elevated glucose levels on anti-viral responses has been previously observed in type I diabetes patients, which showed a decreased in vivo $T$ cell response to influenza antigen [44] and decreased in vitro cytotoxic T cell response to influenza vaccination [45]. Both phenomena were associated with high concentrations of $\mathrm{HbA1c}$, while B cell responses were normal.

However, other viral infections may be easily overlooked, because many-, including reovirus infections, commonly cause only mild symptoms or follow a subclinical course.

Our pathway analysis indicated that the expression profile of T2DM patients contained a viral signature of the Reoviridae family comprising reovirus [26], and Rotavirus [27]. The reovirus signature is derived from in vitro infection of human embryonic kidney cells, while the Rotavirus signature is derived from PBMC from Rotavirus- infected children. Nevertheless, the reovirus signature is more significant. The other virusregulated gene sets included in our analysis; Influenza-, forty CMV-, two HPV- and one HCV-regulated sets of genes were not significantly associated with T2DM, indicating a certain level of specificity for reovirus. Reovirus is a double-stranded RNA virus that is believed to cause mild infections of the upper respiratory and gastrointestinal tract of humans, while Rotavirus (RV) is another ubiquitous double-stranded RNA virus, which may also cause gastroenteritis. Interestingly, reoviruses are known to experimentally induce type 1 diabetes, by inducing insulitis, reduction in insulin content of the pancreas and abnormal glucose tolerance [46, 47]. Likewise, Rotavirus infection is associated with a faster progression of diabetes in diabetes-prone mice [48] and with pancreatic apoptosis and hyperglycemia in nondiabetes-prone mice [49]. Previous studies already pointed towards a role for viruses in development human T1DM. For T1DM it is hypothesized 
Table 5 Transcription factor binding site analysis of differentially expressed genes in T2DM versus MetS patients

\begin{tabular}{|c|c|c|c|}
\hline \multicolumn{4}{|c|}{ A. Analysis of genes that were expressed at significantly higher levels in T2DM versus MetS patients } \\
\hline Name & Number of hits in the submitted regions & Total number of hits on genome & $p$-value \\
\hline HIF1 & 148 & 4,853 & $1.25 \mathrm{E}-12$ \\
\hline MYC & 214 & 9,078 & $1.08 \mathrm{E}-07$ \\
\hline STRA13 & 25 & 466 & 3.06E-07 \\
\hline ARNT & 46 & 1,326 & 2.33E-06 \\
\hline XBP1 & 67 & 2,323 & 8.31E-06 \\
\hline SREBP1 & 74 & 2,807 & 5.46E-05 \\
\hline ATF4 & 176 & 8,147 & 1.33E-04 \\
\hline HES1 & 183 & 8,691 & 3.37E-04 \\
\hline E2F1DP1 & 302 & 15,241 & 3.47E-04 \\
\hline DEC & 79 & 3,322 & $6.99 \mathrm{E}-04$ \\
\hline \multicolumn{4}{|c|}{ B. Analysis of genes that were expressed at significantly lower levels in T2DM versus MetS patients } \\
\hline Name & Number of hits in the submitted regions & Total number of hits on genome & $p$-value \\
\hline GABP & 50 & 2,358 & 2.64E-08 \\
\hline PEA3 & 112 & 7,400 & $5.40 \mathrm{E}-08$ \\
\hline CETS168 & 79 & 4,918 & 4.95E-07 \\
\hline AR & 71 & 4,314 & $7.78 \mathrm{E}-07$ \\
\hline HIF1 & 73 & 4,853 & 1.17E-05 \\
\hline DEC & 54 & 3,322 & 2.04E-05 \\
\hline E2F1DP1 & 180 & 15,241 & $6.43 \mathrm{E}-05$ \\
\hline TFE & 58 & 3,881 & $1.00 \mathrm{E}-04$ \\
\hline MYC & 113 & 9,078 & 2.10E-04 \\
\hline NRF1 & 19 & 919 & $6.45 \mathrm{E}-04$ \\
\hline E2F1DP2 & 140 & 12,122 & $8.78 \mathrm{E}-04$ \\
\hline
\end{tabular}

Significant binding sites are shown with a $p$-value $<0.001$

that viruses contribute to beta cell destruction, in particular enteroviruses are strong candidates [50], because there is a clinically significant association between enterovirus infection and T1DM. In accordance with this hypothesis, enterovirus (echovirus) is able to infect and destroy human beta cells in vitro [51]. Additional evidence is provided by the fact that in more than half of the human T1DM patients, beta cells show clear enteroviral capsid protein vp1 expression, indicative for enteroviral infection, while only $6 \%$ of controls are marginally positive. Interestingly, also 10 out of 25 T2DM patients were positive for enteroviral capsid protein vp1 expression, suggesting that viral infections may contribute to beta cell loss and insulin dependency in T2DM as well [52]. Our results support the hypothesis, using an unbiased approach, that viral infections (potentially reovirus), may contribute to development of insulin-dependent diabetes in T2DM patients.

The fact that the reovirus signature was present in T2DM but not in MetS subjects is in line with the observation that inflammation in general contributes to the development of T2DM [10-12], and supports the finding that inhibition of inflammation (by blockade of
IL-1 signaling) improves HbA1c levels in T2DM patients without changing insulin sensitivity, but not in nondiabetic subjects with MetS [53]. Inhibition of inflammation therefore most likely has beneficial effects on insulin production in T2DM patients only.

Apart from the viral signature in T2DM, systemic inflammation was also indicated by the increased transcript expression of S100A12/ENRAGE, corresponding with the reported increased serum levels of S100A12/ EN-RAGE in T2DM patients [54], CD164, a HIF-1 $\alpha$ response gene [55], encoding a sialomucin expressed on peripheral blood monocyte, involved in adhesion [56], and TLR1. Interestingly, mRNA encoding for the appetite hormone leptin was also increased in T2DM vs MetS, which is normally expressed in adipose tissue, and at higher levels per gram tissue from obese subjects compared to lean individuals $[57,58]$.

In search of transcription factors that may have caused the altered expression profile in T2DM patients, we identified highly enriched transcription factor binding sites for HIF1 and ARNT in genes with an aberrant expression compared to MetS patients (and lean controls). 
Table 6 Genes with altered expression after in vivo exposure to high blood glucose

\begin{tabular}{|c|c|c|c|c|c|c|c|}
\hline \multicolumn{8}{|l|}{ Downregulated genes after hyperglycemia } \\
\hline \multirow[t]{2}{*}{ Gene name } & \multirow[t]{2}{*}{ Symbol } & \multicolumn{2}{|c|}{ Controls $(n=3)$} & \multicolumn{2}{|c|}{ MetS $(n=4)$} & \multicolumn{2}{|c|}{ T2DM $(n=6)$} \\
\hline & & FC & q-value & FC & q-value & FC & q-value \\
\hline Granzyme B & GZMB & 0.42 & 0.00 & 0.71 & 0.00 & 0.97 & 98.95 \\
\hline Granulysin & GNLY & 0.47 & 0.00 & 0.92 & 88.23 & 1.07 & 96.96 \\
\hline Perforin 1 & PRF1 & 0.48 & 0.00 & 0.77 & 75.30 & 0.96 & 98.64 \\
\hline Fibroblast growth factor binding protein 2 & FGFBP2 & 0.50 & 0.00 & 1.00 & 99.70 & 1.17 & 96.96 \\
\hline Chloride intracellular channel 3 & CLIC3 & 0.56 & 0.00 & 0.95 & 93.51 & 1.03 & 98.21 \\
\hline Killer cell immunoglobulinlike receptor, two domains, long cytoplasmic tail, 4 & KIR2DL4 & 0.62 & 0.00 & 0.89 & 65.06 & 1.05 & 96.96 \\
\hline Chromosome 1 open reading frame 162 & C1orf162 & 0.66 & 0.00 & 0.75 & 0.00 & 0.90 & 81.90 \\
\hline Cystatin F (leukocystatin) & CST7 & 0.67 & 0.00 & 1.01 & 97.65 & 1.03 & 98.21 \\
\hline Galectin 1 & LGALS1 & 0.68 & 0.00 & 0.97 & 98.10 & 0.97 & 98.72 \\
\hline FK506 binding protein 5 & FKBP5 & 0.68 & 9.78 & 0.51 & 0.00 & 0.71 & 37.55 \\
\hline TSC22 domain family, member 3 & TSC22D3 & 0.73 & 10.48 & 0.70 & 0.00 & 0.64 & 0.00 \\
\hline Dual specificity phosphatase 1 & DUSP1 & 1.02 & 96.30 & 0.71 & 70.35 & 0.69 & 0.00 \\
\hline Myeloid cell leukemia sequence 1 (BCL2related) & MCL1 & 1.00 & 97.20 & 0.89 & 67.05 & 0.81 & 0.00 \\
\hline \multicolumn{8}{|l|}{ Upregulated genes after hyperglycemia } \\
\hline Interleukin 8 & IL8 & 1.24 & 66.30 & 1.44 & 0.00 & 1.46 & 22.49 \\
\hline HIV1 Tat specific factor 1 pseudogene & LOC401233 & 1.18 & 67.90 & 1.24 & 0.00 & 1.07 & 96.96 \\
\hline
\end{tabular}

FC indicates fold change compare to baseline levels. q-value indicates the false discovery rate (\%). Significant changes are indicated in bold ( $\mathrm{q}<5 \%$ ). Gene symbols indicated in bold are cytotoxicity related, and visualized in Fig. 4

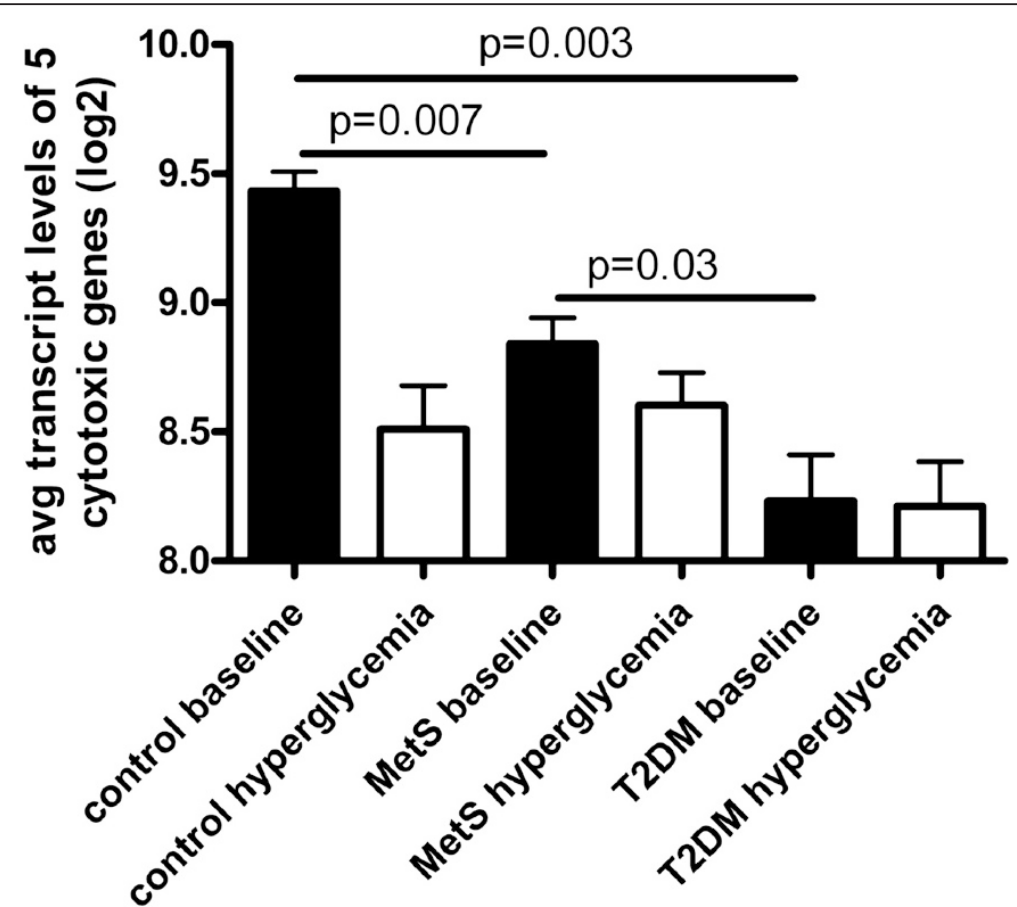

Fig. 4 Visualization of the reduced expression of cytotoxicity related genes, in healthy controls after hyperglycemia (derived from Table 6). In patients with T2DM the expression is already low and does not further decrease after hyperglycemia. The average expression of 5 cytotoxicity related genes measured by microarray analysis is shown in controls $(n=3)$, MetS $(n=4)$ and T2DM $(n=6)$. Error bars indicate the standard error of the mean gene expression levels of the individuals within the groups. $p$-values are indicated for the comparisons between baseline levels, calculated by unpaired T-test 
Table 7 Characteristics of the groups of patients used for confirmation by real-time pcr

\begin{tabular}{|c|c|c|c|c|c|c|}
\hline & T2DM & MetS & Obese controls & $p$-value & $p$-value & $p$-value \\
\hline & $n=6$ & $n=8$ & $n=4$ & $\mathrm{DM} 2$ vs OC & DM2 vs MetS & MetS vs OC \\
\hline Age (years) & 59.2 & 59.9 & 59.3 & $p=0.99$ & 0.82 & 0.87 \\
\hline $\operatorname{Sex}(m / f)$ & $6 / 0$ & $7 / 1$ & $4 / 0$ & 1 & 1 & 1 \\
\hline Height (cm) & 172.2 & 178.5 & 178.0 & 0.10 & 0.16 & 0.94 \\
\hline Weight (kg) & 84.2 & 103.2 & 101.7 & 0.006 & 0.09 & 0.87 \\
\hline BMI (kg/m2) & 28.5 & 32.2 & 31.7 & 0.07 & 0.24 & 0.94 \\
\hline Waist (cm) & 102.1 & 112.3 & 118.0 & 0.02 & 0.26 & 0.58 \\
\hline Syst BP (mm Hg) & 143.5 & 137.7 & 126.5 & 0.09 & 0.42 & 0.09 \\
\hline Diast BP $(\mathrm{mm} \mathrm{Hg})$ & 85.3 & 86.3 & 78.8 & 0.33 & 0.76 & 0.19 \\
\hline FPG $(\mathrm{mmol} / \mathrm{l})$ & 8.4 & 6.4 & 5.5 & 0.0002 & $<0.0001$ & 0.008 \\
\hline $\mathrm{HbA1c}(\%)$ & 6.6 & 5.8 & 5.4 & 0.01 & 0.03 & 0.22 \\
\hline Tot Chol (mmol/l) & 4.8 & 5.2 & 5.0 & 0.79 & 0.35 & 0.60 \\
\hline $\mathrm{HDL}(\mathrm{mmol} / \mathrm{l})$ & 1.1 & 1.6 & 1.5 & 0.002 & 0.007 & 0.85 \\
\hline LDL (mmol/l) & 3 & 3.1 & 3.1 & 0.85 & 0.69 & 0.90 \\
\hline TG $(\mathrm{mmol} / \mathrm{l})$ & 1.9 & 1.1 & 0.8 & 0.04 & 0.03 & 0.08 \\
\hline
\end{tabular}

T2DM patients are identical to Table 1, the MetS group is expanded by 4 individuals compared to Table 1. All comparisons were performed by T-test, or Fisher's exact for sex. Significant differences $(p<0.05)$ are indicated in bold. When variances were different, a Welch correction was applied

HIF1 is a heterodimer consisting of HIF- $1 \alpha$ and constitutively expressed ARNT (also termed HIF-1 $\beta$ ) and regulates the response to hypoxia and growth factors by controlling energy metabolism [59]. Indeed, gene ontology analysis confirmed that metabolic processes were affected in T2DM patients compared to circulating cells from MetS subjects. Affected metabolic processes have been demonstrated before in blood cells from T2DM versus MetS, or versus nondiabetic controls [60, 61], although the subjects were not matched for BMI as in our study. It may not be surprising to identify metabolic processes in metabolically disturbed patients, however it does indicate that these metabolic changes are reflected in the gene expression profile of peripheral blood cells and can thus be monitored. Interestingly, HIF-1 $\alpha$ activity, experimentally induced upon intermittent hypoxia, increases plasma triglycerides through upregulation of sterol regulatory element binding protein (SREBP)-1 activity in the liver [62]. These results correspond to our findings that T2DM patients show higher HIF- $1 \alpha$ activity, associated with higher plasma triglyceride levels. Furthermore, the genes showing higher transcript levels in T2DM patients not only contained binding sites for HIF- $1 \alpha$ and ARNT, but also for SREBP-1, thus reminiscent of the molecular switches during hypoxia in the liver.

The previously described reduced expression of genes involved in electron transport chain and oxidative phosphorylation in PBMC from T2DM vs young lean controls [15] is consistent with increased HIF- $1 \alpha$ activity in T2DM. We confirmed the reduced expression of electron transport chain and oxidative phosphorylation genes in T2DM when we compared these patients to young lean controls (Additional file 1B). It is quite remarkable that the analysis of only three controls and six T2DM patients results in such highly significant pathways which are consistent with previously published data.

It is not quite clear what exactly caused the increased activity of HIF-1 $\alpha$ in T2DM patients. In normal physiology, hypoxia regulates HIF- $1 \alpha$ activity on the protein level by preventing its degradation by an oxygendependent mechanism, reviewed in [63]. However, it has been suggested before that hyperglycemia mimics the effects of hypoxia, in terms of an increased cytosolic ratio of NADH/NAD+, referred to as pseudo hypoxia in diabetes patients [64]. Reactive oxygen species (ROS) may also stabilize HIF- $1 \alpha$ under normoxic conditions, resulting in increased glycolytic metabolism and increased NADH/NAD+ ratio [65]. High dietary fat intake and obesity causes increased release of skeletal muscle mitochondrial ROS species (H2O2) accompanied by a change in redox environment to a more oxidized state (generally referred to as oxidative stress) and insulin resistance in mice and humans [66] Targeting the altered redox state in mice by neutralization of $\mathrm{H} 2 \mathrm{O} 2$ by an antioxidant or by overexpression of catalase in mitochondria of muscle cells prevents high fat diet-induced insulin resistance [66]. The two-fold increased expression of catalase in circulating cells from T2DM patients compared to MetS suggests that a compensatory mechanism for increased oxidative damage is activated in T2DM. Therefore, it might very well be that in T2DM patients, chronic hyperglycemia 

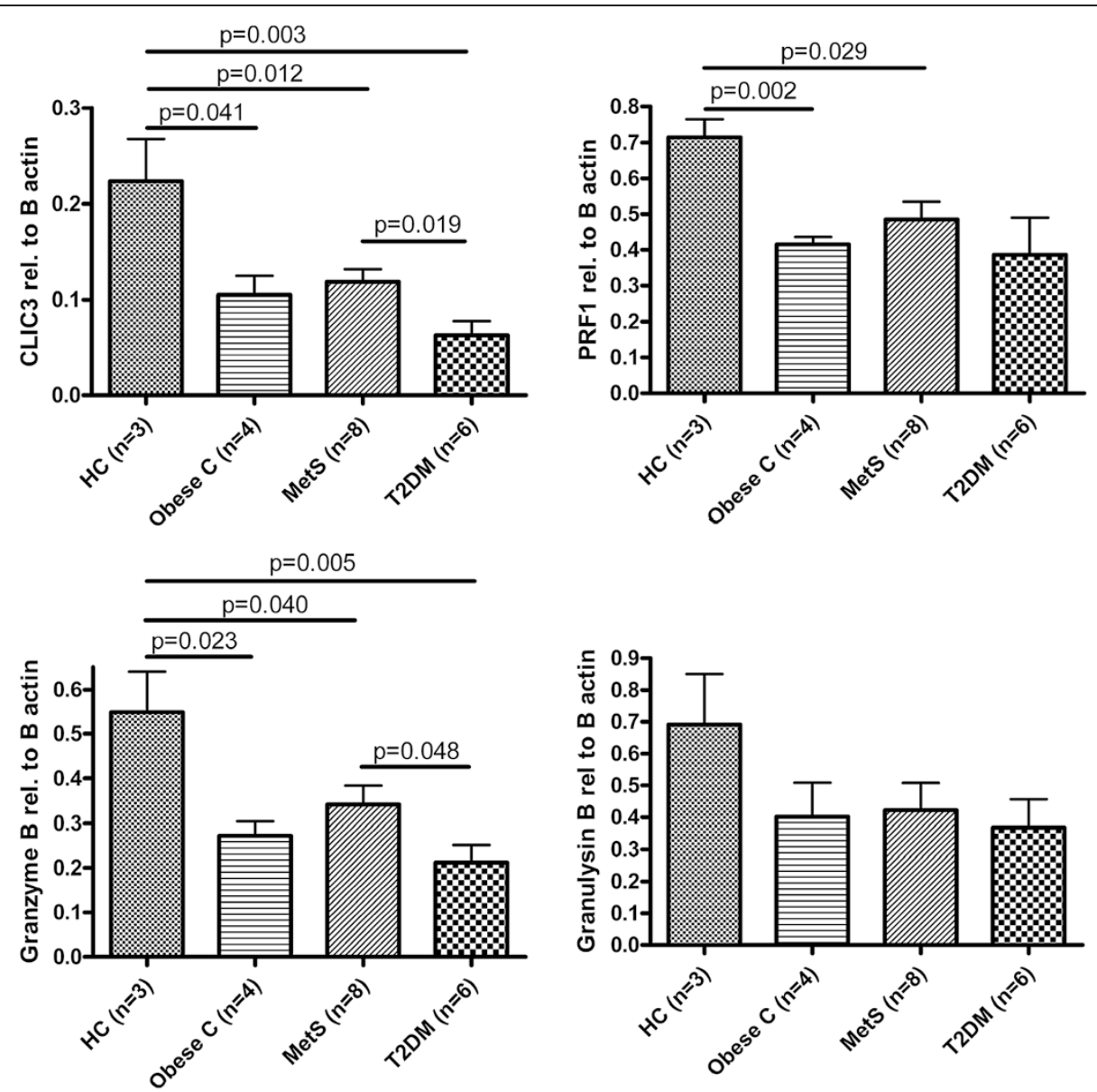

Fig. 5 Baseline levels of cytotoxicity-related genes determined by real-time pcr in lean controls, obese controls, MetS and T2DM patients. mRNA levels of cytotoxicity genes are expressed relative to $\beta$-actin as indicated. Error bars indicate the standard error of the mean gene expression levels of the individuals within the groups. $p$-values are indicated for the comparisons between baseline levels, calculated by unpaired T-test

and oxidative stress contributes to the HIF-1 $\alpha$ - regulated metabolic change in peripheral blood cells. Indeed, prolonged high glucose levels in vivo induces the expression of the HIF-1 $\alpha$-responsive gene VEGF and vascular dysfunction in rats [67]. Interestingly, adipocyte-specific disruption of ARNT or disruption of HIF- $1 \alpha$ in mice results in similar metabolic phenotypes. In both mouse models the high fat diet-induced abnormalities are reduced, including diminished fat formation, protection from obesity and insulin resistance [68], suggesting a role for HIF1 in the pathogenesis of obesity and insulin resistance.

The gene expression profile in peripheral blood seems to partially mimic the profile of adipocytes, with respect to HIF-1 $\alpha$ activity and leptin expression (both associated with obesity), and to partially mimic the response in the liver, reflected by the enriched binding sites for SREBP-1 normally activated by HIF- $1 \alpha$ in the liver. These findings are in line with the suggestion that altered gene expression in specific organs, is reflected in peripheral blood cells [14].

\section{Conclusions}

Using an unbiased approach we have revealed that a hyperglycemic state affects the cytotoxic immune capacity. The reduced cytotoxic potential may render the T2DM patients less capable to clear viral infections. This suggestion is supported by the identification of a reovirus expression signature in T2DM patients. It is tempting to speculate that viral infections in T2DM fuel systemic inflammatory processes and may even lead to infection of pancreatic beta cells, as has been shown in experimental animals, and thus contribute to the induction of insulitis and insulindependent diabetes.

\section{Additional files}

Additional file 1: Genes expressed at higher levels in T2DM patients compared to individuals with MetS. Statistical analysis was performed using the SAM package. A q value $<5 \%$ is considered significant. 
Additional file 2: Genes expressed at lower levels in T2DM patients compared to individuals with MetS. Statistical analysis was performed using the SAM package. A q value $<5 \%$ is considered significant.

\section{Competing interests}

The authors declare that they have no competing interests.

\section{Authors' contributions}

CTMPK participated in the design of the study, analyzed the data and drafted the manuscript. WJC, MCMB, DHR, NJZ, REG, LB performed the hyperglycemic clamps, participated in coordination of the study and helped to draft the manuscript. JMB processed blood samples and performed gene expression quantification. EHS partly coordinated the study, and helped to draft the manuscript. MD and AJGH designed and supervised the study, and contributed to drafting the manuscript. All authors read and approved the final manuscript.

\section{Author details}

'Department of Molecular Cell Biology \& Immunology, VU University Medical Center, Amsterdam, The Netherlands. ${ }^{2}$ Department of Internal Medicine, Diabetes Center, VU University Medical Center, Amsterdam, The Netherlands.

\section{Received: 25 September 2014 Accepted: 30 April 2015}

\section{Published online: 09 May 2015}

\section{References}

1. Alberti KG, Eckel RH, Grundy SM, Zimmet PZ, Cleeman Jl, Donato KA, et al. Harmonizing the metabolic syndrome: a joint interim statement of the International Diabetes Federation Task Force on Epidemiology and Prevention; National Heart, Lung, and Blood Institute; American Heart Association; World Heart Federation; International Atherosclerosis Society; and International Association for the Study of Obesity. Circulation. 2009;120:1640-5

2. Laakso M. Cardiovascular disease in type 2 diabetes from population to man to mechanisms: the Kelly West Award Lecture 2008. Diabetes Care. 2010;33:442-9.

3. Turnbull FM, Abraira C, Anderson RJ, Byington RP, Chalmers JP, Duckworth WC, et al. Intensive glucose control and macrovascular outcomes in type 2 diabetes. Diabetologia. 2009;52:2288-98.

4. Standl E. Statins and beyond: concurrent strategies for prevention of cardiovascular disease in patients with type 2 diabetes. Diab Vasc Dis Res. 2013:10:99-114.

5. Coutinho M, Gerstein HC, Wang Y, Yusuf S. The relationship between glucose and incident cardiovascular events. A metaregression analysis of published data from 20 studies of 95,783 individuals followed for 12.4 years. Diabetes Care. 1999;22:233-40.

6. DECODE Study Group tEDEG. Glucose tolerance and cardiovascular mortality: comparison of fasting and 2-h diagnostic criteria. Arch Intern Med. 2001;161:397-405.

7. Donath MY, Shoelson SE. Type 2 diabetes as an inflammatory disease. Nat Rev Immunol. 2011;11:98-107.

8. Richardson VR, Smith KA, Carter AM. Adipose tissue inflammation: feeding the development of type 2 diabetes mellitus. Immunobiology. 2013;218:1497-504

9. Romeo GR, Lee J, Shoelson SE. Metabolic syndrome, insulin resistance, and roles of inflammation-mechanisms and therapeutic targets. Arterioscler Thromb Vasc Biol. 2012:32:1771-6.

10. Donath MY, Schumann DM, Faulenbach M, Ellingsgaard $H$, Perren A, Ehses JA. Islet inflammation in type 2 diabetes: from metabolic stress to therapy. Diabetes Care. 2008;31 Suppl 2:S161-4.

11. Ehses JA, Perren A, Eppler E, Ribaux P, Pospisilik JA, Maor-Cahn R, et al. Increased number of islet-associated macrophages in type 2 diabetes. Diabetes. 2007;56:2356-70

12. Eguchi K, Manabe I. Macrophages and islet inflammation in type 2 diabetes. Diabetes Obes Metab. 2013;15 Suppl 3:152-8.

13. Kempf K, Rose B, Herder C, Haastert B, Fusbahn-Laufenburg A, Reifferscheid A, et al. The metabolic syndrome sensitizes leukocytes for glucose-induced immune gene expression. J Mol Med (Berl). 2007;85:389-96.

14. Liew CC, Ma J, Tang HC, Zheng R, Dempsey AA. The peripheral blood transcriptome dynamically reflects system wide biology: a potential diagnostic tool. J Lab Clin Med. 2006;147:126-32.
15. Takamura T, Honda M, Sakai $Y$, Ando H, Shimizu A, Ota T, et al. Gene expression profiles in peripheral blood mononuclear cells reflect the pathophysiology of type 2 diabetes. Biochem Biophys Res Commun. 2007:361:379-84.

16. Mootha VK, Lindgren CM, Eriksson KF, Subramanian A, Sihag S, Lehar J, et al. PGC-1alpha-responsive genes involved in oxidative phosphorylation are coordinately downregulated in human diabetes. Nat Genet. 2003;34:267-73.

17. Alberti KG, Zimmet P, Shaw J. Metabolic syndrome-a new world-wide definition. A Consensus Statement from the International Diabetes Federation. Diabet Med. 2006;23:469-80.

18. Bunck MC, Diamant M, Corner A, Eliasson B, Malloy JL, Shaginian RM, et al. One-year treatment with exenatide improves beta-cell function, compared with insulin glargine, in metformin-treated type 2 diabetic patients: a randomized, controlled trial. Diabetes Care. 2009;32:762-8.

19. Bolstad BM, Irizarry RA, Astrand M, Speed TP. A comparison of normalization methods for high density oligonucleotide array data based on variance and bias. Bioinformatics. 2003:19:185-93.

20. Tusher VG, Tibshirani R, Chu G. Significance analysis of microarrays applied to the ionizing radiation response. Proc Natl Acad Sci U S A. 2001;98:5116-21.

21. Eisen MB, Spellman PT, Brown PO, Botstein D. Cluster analysis and display of genome-wide expression patterns. Proc Natl Acad Sci U S A. 1998;95:14863-8.

22. Mi H, Muruganujan A, Thomas PD. PANTHER in 2013: modeling the evolution of gene function, and other gene attributes, in the context of phylogenetic trees. Nucleic Acids Res. 2013;41:D377-86.

23. Subramanian A, Tamayo P, Mootha VK, Mukherjee S, Ebert BL, Gillette MA, et al. Gene set enrichment analysis: a knowledge-based approach for interpreting genome-wide expression profiles. Proc Natl Acad Sci U S A. 2005;102:15545-50.

24. van der Pouw Kraan TC, van der Laan AM, Piek JJ, Horrevoets AJ. Surfing the data tsunami, a bioinformatic dissection of the proangiogenic monocyte. Vascul Pharmacol. 2012;56:297-305.

25. Zambon AC, Zhang L, Minovitsky S, Kanter JR, Prabhakar S, Salomonis N, et al. Gene expression patterns define key transcriptional events in cell-cycle regulation by CAMP and protein kinase A. Proc Natl Acad Sci U S A. 2005:102:8561-6.

26. DeBiasi RL, Clarke P, Meintzer S, Jotte R, Kleinschmidt-Demasters BK, Johnson GL, et al. Reovirus-induced alteration in expression of apoptosis and DNA repair genes with potential roles in viral pathogenesis. J Virol. 2003;77:8934-47.

27. Wang Y, Dennehy PH, Keyserling HL, Tang K, Gentsch JR, Glass Rl, et al. Rotavirus infection alters peripheral T-cell homeostasis in children with acute diarrhea. J Virol. 2007:81:3904-12.

28. Ramilo O, Allman W, Chung W, Mejias A, Ardura M, Glaser C, et al. Gene expression patterns in blood leukocytes discriminate patients with acute infections. Blood. 2007;109:2066-77.

29. Ji X, Cheung R, Cooper S, Li Q, Greenberg HB, He XS. Interferon alfa regulated gene expression in patients initiating interferon treatment for chronic hepatitis C. Hepatology. 2003;37:610-21.

30. Grandvaux N, Servant MJ, tenOever B, Sen GC, Balachandran S, Barber GN, et al. Transcriptional profiling of interferon regulatory factor 3 target genes: direct involvement in the regulation of interferon-stimulated genes. J Virol. 2002;76:5532-9.

31. Dybkaer K, lqbal J, Zhou G, Geng H, Xiao L, Schmitz A, et al. Genome wide transcriptional analysis of resting and IL2 activated human natural killer cells: gene expression signatures indicative of novel molecular signaling pathways. BMC Genomics. 2007;8:230-47.

32. Obata-Onai A, Hashimoto S, Onai N, Kurachi M, Nagai S, Shizuno K, et al. Comprehensive gene expression analysis of human NK cells and CD8(+) T lymphocytes. Int Immunol. 2002;14:1085-98.

33. Correia MP, Costa AV, Uhrberg M, Cardoso EM, Arosa FA. IL-15 induces CD8 + T cells to acquire functional NK receptors capable of modulating cytotoxicity and cytokine secretion. Immunobiology. 2011;216:604-12.

34. Palmer C, Diehn M, Alizadeh AA, Brown PO. Cell-type specific gene expression profiles of leukocytes in human peripheral blood. BMC Genomics. 2006;7:115.

35. Bouma G, Baggen JM, van Bodegraven AA, Mulder CJ, Kraal G, Zwiers A, et al. Thiopurine treatment in patients with Crohn's disease leads to a selective reduction of an effector cytotoxic gene expression signature revealed by whole-genome expression profiling. Mol Immunol. 2013;54:472-81. 
36. Bloom ET, Umehara H, Bleackley RC, Okumura K, Mostowski H, Babbitt JT. Age-related decrement in cytotoxic T lymphocyte (CTL) activity is associated with decreased levels of mRNA encoded by two CTL-associated serine esterase genes and the perforin gene in mice. Eur J Immunol. 1990;20:2309-16.

37. Khan N, Hislop A, Gudgeon N, Cobbold M, Khanna R, Nayak L, et al. Herpesvirus-specific CD8 T cell immunity in old age: cytomegalovirus impairs the response to a coresident EBV infection. J Immunol. 2004;173:7481-9.

38. Dimayuga PC, Chyu KY, Lio WM, Zhao X, Yano J, Zhou J, et al. Reduced neointima formation after arterial injury in CD4-/- mice is mediated by CD8 + CD28hi T cells. J Am Heart Assoc. 2013;2, e000155.

39. Chyu KY, Zhao X, Dimayuga PC, Zhou J, Li X, Yano J, et al. CD8+ T cells mediate the athero-protective effect of immunization with an ApoB-100 peptide. PLoS One. 2012;7, e30780.

40. Smyth MJ, Kelly JM, Sutton VR, Davis JE, Browne KA, Sayers TJ, et al. Unlocking the secrets of cytotoxic granule proteins. J Leukoc Biol. 2001;70:18-29.

41. Guidotti LG, Chisari FV. Noncytolytic control of viral infections by the innate and adaptive immune response. Annu Rev Immunol. 2001;19:65-91.

42. Nicolucci A. Epidemiological aspects of neoplasms in diabetes. Acta Diabetol. 2010:47:87-95.

43. Lin TM, Chen WJ, Chen HY, Wang PW, Eng HL. Increased incidence of cytomegalovirus but not Chlamydia pneumoniae in atherosclerotic lesions of arteries of lower extremities from patients with diabetes mellitus undergoing amputation. J Clin Pathol. 2003:56:429-32.

44. Diepersloot RJ, Bouter KP, Beyer WE, Hoekstra JB, Masurel N. Humoral immune response and delayed type hypersensitivity to influenza vaccine in patients with diabetes mellitus. Diabetologia. 1987;30:397-401.

45. Diepersloot RJ, Bouter KP, Van BR, Lucas CJ, Masurel N, Erkelens DW. Cytotoxic T-cell response to influenza A subunit vaccine in patients with type 1 diabetes mellitus. Neth J Med. 1989;35:68-75.

46. Onodera $T$, Jenson AB, Yoon JW, Notkins AL. Virus-induced diabetes mellitus: reovirus infection of pancreatic beta cells in mice. Science. 1978;201:529-31.

47. Jun HS, Yoon JW. A new look at viruses in type 1 diabetes. Diabetes Metab Res Rev. 2003;19:8-31.

48. Graham KL, Sanders N, Tan Y, Allison J, Kay TW, Coulson BS. Rotavirus infection accelerates type 1 diabetes in mice with established insulitis. J Virol. 2008:82:6139-49.

49. Honeyman MC, Laine D, Zhan Y, Londrigan S, Kirkwood C, Harrison LC. Rotavirus infection induces transient pancreatic involution and hyperglycemia in weanling mice. PLoS One. 2014;9, e106560.

50. Yeung WC, Rawlinson WD, Craig ME. Enterovirus infection and type 1 diabetes mellitus: systematic review and meta-analysis of observational molecular studies. BMJ. 2011;342:d35.

51. Ylipaasto P, Smura T, Gopalacharyulu P, Paananen A, Seppanen-Laakso T, Kaijalainen $S$, et al. Enterovirus-induced gene expression profile is critical for human pancreatic islet destruction. Diabetologia. 2012;55:3273-83.

52. Richardson SJ, Willcox A, Bone AJ, Foulis AK, Morgan NG. The prevalence of enteroviral capsid protein vp1 immunostaining in pancreatic islets in human type 1 diabetes. Diabetologia. 2009;52:1143-51.

53. van Asseldonk EJ, Stienstra R, Koenen TB, Joosten LA, Netea MG, Tack CJ. Treatment with Anakinra improves disposition index but not insulin sensitivity in nondiabetic subjects with the metabolic syndrome: a randomized, double-blind, placebo-controlled study. J Clin Endocrinol Metab. 2011;96:2119-26.

54. Kosaki A, Hasegawa T, Kimura T, lida K, Hitomi J, Matsubara H, et al. Increased plasma S100A12 (EN-RAGE) levels in patients with type 2 diabetes. J Clin Endocrinol Metab. 2004:89:5423-8.

55. Tang J, Luo Z, Zhou G, Song C, Yu F, Xiang J, et al. Cis-regulatory functions of overlapping HIF-1alpha/E-box/AP-1-like sequences of CD164. BMC Mol Biol. 2011;12:44-54.

56. Watt SM, Buhring HJ, Rappold I, Chan JY, Lee-Prudhoe J, Jones T, et al. CD164, a novel sialomucin on CD34(+) and erythroid subsets, is located on human chromosome 6q21. Blood. 1998;92:849-66.

57. Fried SK, Ricci MR, Russell CD, Laferrere B. Regulation of leptin production in humans. J Nutr. 2000:130:3127S-31.

58. Galic S, Oakhill JS, Steinberg GR. Adipose tissue as an endocrine organ. Mol Cell Endocrinol. 2010:316:129-39.

59. Semenza GL. Targeting HIF-1 for cancer therapy. Nat Rev Cancer. 2003:3:721-32

60. Manoel-Caetano FS, Xavier DJ, Evangelista AF, Takahashi P, Collares CV, Puthier D, et al. Gene expression profiles displayed by peripheral blood mononuclear cells from patients with type 2 diabetes mellitus focusing on biological processes implicated on the pathogenesis of the disease. Gene. 2012:511:151-60.

61. Grayson BL, Wang L, Aune TM. Peripheral blood gene expression profiles in metabolic syndrome, coronary artery disease and type 2 diabetes. Genes Immun. 2011;12:341-51.

62. Li J, Bosch-Marce M, Nanayakkara A, Savransky V, Fried SK, Semenza GL, et al. Altered metabolic responses to intermittent hypoxia in mice with partial deficiency of hypoxia-inducible factor-1alpha. Physiol Genomics. 2006;25:450-7.

63. Imtiyaz HZ, Simon MC. Hypoxia-inducible factors as essential regulators of inflammation. Curr Top Microbiol Immunol. 2010;345:105-20.

64. Williamson JR, Chang K, Frangos M, Hasan KS, Ido Y, Kawamura T, et al. Hyperglycemic pseudohypoxia and diabetic complications. Diabetes. 1993;42:801-13.

65. Chiarugi A, Dolle C, Felici R, Ziegler M. The NAD metabolome-a key determinant of cancer cell biology. Nat Rev Cancer. 2012;12:741-52.

66. Anderson EJ, Lustig ME, Boyle KE, Woodlief TL, Kane DA, Lin CT, et al. Mitochondrial $\mathrm{H} 2 \mathrm{O} 2$ emission and cellular redox state link excess fat intake to insulin resistance in both rodents and humans. J Clin Invest. 2009;119:573-81.

67. Tilton RG, Kawamura T, Chang KC, Ido Y, Bjercke RJ, Stephan CC, et al. Vascular dysfunction induced by elevated glucose levels in rats is mediated by vascular endothelial growth factor. J Clin Invest. 1997;99:2192-202.

68. Jiang C, Qu A, Matsubara T, Chanturiya T, Jou W, Gavrilova O, et a. Disruption of hypoxia-inducible factor 1 in adipocytes improves insulin sensitivity and decreases adiposity in high-fat diet-fed mice. Diabetes. 2011;60:2484-95.

\section{Submit your next manuscript to BioMed Central and take full advantage of:}

- Convenient online submission

- Thorough peer review

- No space constraints or color figure charges

- Immediate publication on acceptance

- Inclusion in PubMed, CAS, Scopus and Google Scholar

- Research which is freely available for redistribution

Submit your manuscript at www.biomedcentral.com/submit 